\title{
Keeping predators out: testing fences to reduce livestock depredation at night-time corrals
}

\author{
Gustaf Samelius, Kulbhushansingh Suryananshi, Jens Frank \\ Bayarjargal AgvaAntseren, Erdenechimeg BaAsandamba \\ TSERENNADMid Mijiddorj, ÖrJAn JOHANSSON \\ LKHAgVASUMBEREL TUMURSUKh and Charudut Mishra
}

\begin{abstract}
Livestock depredation by large carnivores is a global conservation challenge, and mitigation measures to reduce livestock losses are crucial for the coexistence of large carnivores and people. Various measures are employed to reduce livestock depredation but their effectiveness has rarely been tested. In this study, we tested the effectiveness of tall fences to reduce livestock losses to snow leopards Panthera uncia and wolves Canis lupus at night-time corrals at the winter camps of livestock herders in the Tost Mountains in southern Mongolia. Self-reported livestock losses at the fenced corrals were reduced from a mean loss of 3.9 goats and sheep per family and winter prior to the study to zero losses in the two winters of the study. In contrast, self-reported livestock losses in winter pastures, and during the rest of the year, when herders used different camps, remained high, which indicates that livestock losses were reduced because of the fences, not because of temporal variation in predation pressure. Herder attitudes towards snow leopards were positive and remained positive during the study, whereas attitudes towards wolves, which attacked livestock also in summer when herders moved out on the steppes, were negative and worsened during the study. This study showed that tall fences can be very effective at reducing night-time losses at corrals and we conclude that fences can be an important tool for snow leopard conservation and for facilitating the coexistence of snow leopards and people.
\end{abstract}

GUSTAF SAMELIUS ${ }^{*}+$ (Corresponding author, (D) orcid.org/0000-0002-1067-9796),

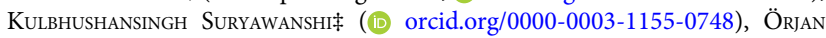
Johansson* (10) orcid.org/0000-0002-9977-0405) and Charudutt Mishra Snow Leopard Trust, 4649 Sunnyside Avenue North, Seattle, USA

E-mail gustaf@snowleopard.org

Jens Frank Grimsö Wildlife Research Station, Swedish University of Agricultural Sciences, Riddarhyttan, Sweden

Bayarjargal Agvantseren, Erdenechimeg BaAsandamba, Tserennadmid Mijiddorj and Lkhagvasumberel Tumursukh Snow Leopard Conservation Foundation, Ulaanbaatar, Mongolia

*Also at: Grimsö Wildlife Research Station, Swedish University of Agricultural Sciences, Riddarhyttan, Sweden

$\dagger$ Also at: Nordens Ark, Hunnebostrand, Sweden

¥Also at: Nature Conservation Foundation, Mysore, India

Received 11 January 2019. Revision requested 12 February 2019

Accepted 1 May 2019. First published online 10 February 2020.
Keywords Canis lupus, carnivore conservation, coexistence, conflict mitigation, conservation conflict, livestock depredation, Panthera uncia, preventative measure

Supplementary material for this article is available at doi.org/10.1017/So030605319000565

\section{Introduction}

T ivestock depredation by large carnivores is a major conservation concern that results in economic loss and emotional trauma for livestock owners and can lead to retaliatory and preventive killing of carnivores (Treves \& Karanth, 2003; Woodroffe et al., 2005). Developing measures to reduce livestock losses is thus crucial for successful conservation of large carnivores and for establishing conditions that facilitate their coexistence with people (Treves \& Karanth, 2003). Numerous measures have been developed to reduce livestock losses (e.g. barriers, deterrents and livestock guarding) but their effectiveness has rarely been tested (Inskip \& Zimmermann, 2009; Eklund et al., 2017; van Eeden et al., 2018).

Livestock depredation by snow leopards Panthera uncia and wolves Canis lupus is a concern in the mountains of central Asia where livestock herding is the main occupation of local people (Mishra et al., 2003; Li et al., 2013; Aryal et al., 2014). Conservation actions to reduce and compensate for livestock losses to these predators include insurance programmes, handicraft programmes to provide supplemental income, and predator proofing of small pens and houses where livestock holdings are small and can be kept inside these structures at night (Mishra et al., 2003; Jackson \& Wangchuck, 2004). However, there are currently no efficient means to reduce night-time losses for large livestock holdings where it is not possible or economically feasible to build predator-proof corrals or other structures that can hold large livestock herds (but see Mohammad et al., 2016 for building walled structures that can hold up to 700 livestock). Predator attacks at night-time corrals and other night-time holdings can be devastating to herders as they often result in mass killings that have a large impact on herder economy and emotions and thereby also herder attitudes towards large carnivores in general (Jackson \& 


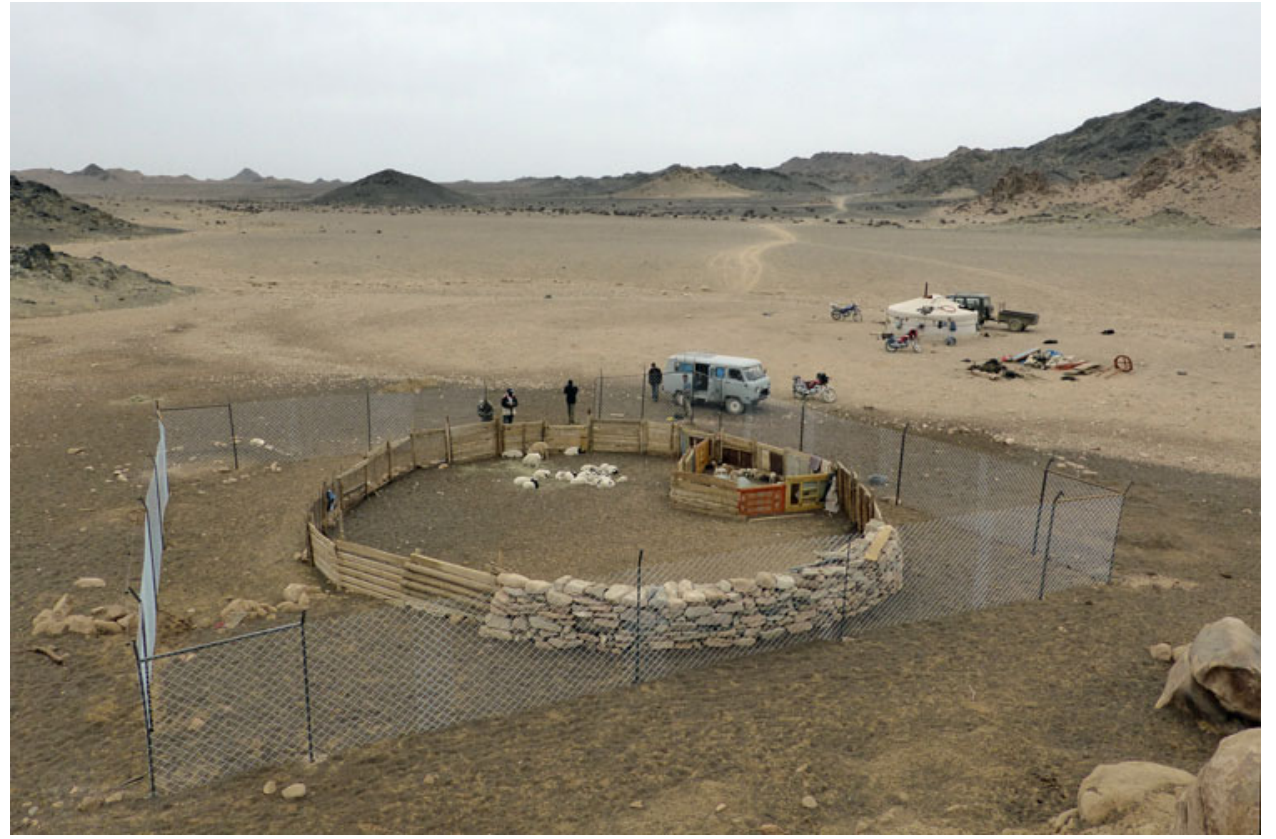

Plate 1 A traditional corral in the Tost Mountains in southern Mongolia, with a fence built around it to reduce livestock depredation by snow leopards Panthera uncia and wolves Canis lupus. The purpose of the traditional corrals is not to keep predators out but to keep the herd together and to provide shelter from the wind.
Wangchuck, 2004). The development and implementation of effective means to reduce night-time losses for large livestock holdings is therefore important for establishing conditions that enable coexistence of carnivores and livestock herders.

The objective of this study was to test the effectiveness of tall fences to reduce livestock losses at night-time corrals and to examine whether these fences affected herder attitudes towards snow leopards and wolves. Specifically, we built $2 \mathrm{~m}$ tall fences at night-time corrals and we compared self-reported livestock losses and herder attitudes before and after the fences were built.

\section{Study area}

We conducted this study in the Tost Mountains in South Gobi, Mongolia, during April 2014-September 2016. Annual precipitation is $<130 \mathrm{~mm}$, temperature range is c. $-35-40{ }^{\circ} \mathrm{C}$ and strong winds are common throughout the year. The area is home to c. 90 semi-nomadic herder families who move c. 2-4 times per year, with most herders staying in the mountains in winter (early November-late March) and in the surrounding steppes during the rest of the year (Mijiddorj et al., 2018). Livestock comprised mostly of goats Capra aegagrus and sheep Ovis aries but herders also kept horses Equus ferus caballus and camels Camelus bactrianus. Goats and sheep were herded during the day and kept at corrals near herder camps at night (Mijiddorj et al., 2018). Horses and camels were largely free-ranging and not brought back to herder camps at night (Mijiddorj et al., 2018). Traditional corrals are generally made of stone and wood, with walls seldom higher than $1 \mathrm{~m}$
(Plate 1). The main purpose of traditional corrals is not to keep predators out but to keep the herd together and provide shelter from the wind. Large carnivores in the study area included snow leopards, wolves and occasionally lynxes Lynx lynx. Snow leopards occurred almost exclusively in the mountains, so herders generally lost herded livestock (goats and sheep) to snow leopards only in winter (Johansson et al., 2015). Wolves occurred both in the mountains and on the steppes and attacked herded livestock throughout the year.

\section{Methods}

\section{Surveys on livestock losses and herder attitudes}

We interviewed 60 herder families on losses of herded livestock and attitudes towards snow leopards and wolves in March 2014. Later in the spring and summer 2014, we built 10 fences at 10 winter camps with a high number of self-reported losses (Fig. 1). These camps were identified jointly by the herder community at a workshop in the Tost Mountains in April 2014. We conducted the survey of self-reported losses and attitudes before we discussed our planned intervention with the herders, to avoid potential bias arising from expectations to receive fences. Because we conducted the survey of self-reported losses and attitudes before identifying localities where fences should be built, three families that received fences were not included in the survey prior to building the fences (i.e. sample size was reduced from 10 to 7 for analyses of effects of fenced corrals on herder attitudes). Our attitude survey followed the protocol by Suryawanshi et al. (2014), with attitude scores ranging from -8 (very negative) to +8 (very positive), 


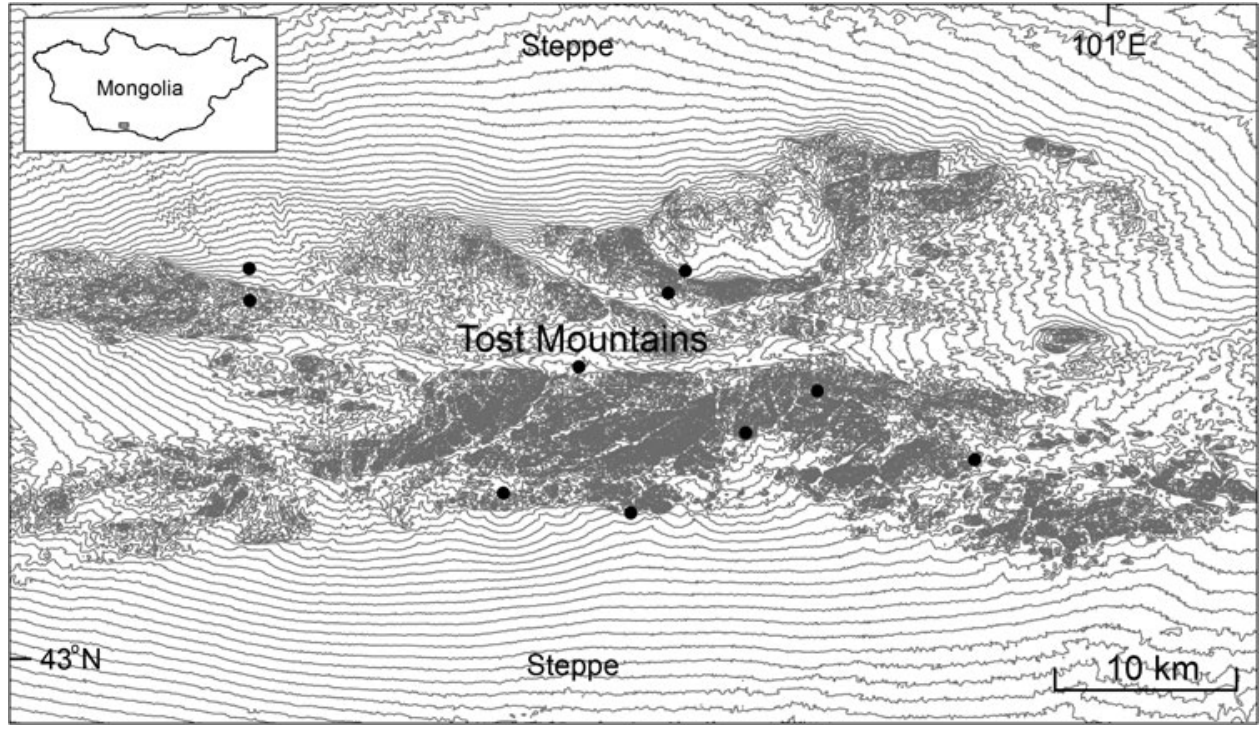

FIG. 1 Location of the fences (black circles) built at winter camps in the Tost Mountains, Mongolia, in the spring and summer of 2014. Thin grey lines are contour lines. All but one of the families that received fences moved to the steppes to the north and south of the Tost Mountains during the summer. o being a neutral score and the sum of scores for all questions used to measure herder attitudes (Supplementary Table 1).

We performed follow-up surveys of self-reported losses of herded livestock for the families that received fences, in the spring and summer of 2015 and 2016. In the summer of 2016, we also repeated the survey on herders' attitudes towards snow leopards and wolves, interviewing families who had received fences and a control group of 10 herder families.

Although livestock losses described in this study are selfreported, we suggest that the numbers are relatively accurate because a large number of the livestock losses in the area are inspected via an insurance programme for compensation purposes (see Mishra et al., 2003, 2016 for details on the insurance programme). We therefore refer to self-reported livestock losses as livestock losses hereafter.

\section{Design of fences}

Fences were $18 \times 18 \mathrm{~m}$ in size and consisted of $2 \mathrm{~m}$ tall aluminium nets supported by metal poles. We reinforced the corners of the fences with horizontal poles and a diagonal cross-piece at the top (Fig. 2). Fences were equipped with an electrical wire at the top (c. $30 \mathrm{~cm}$ above the edge of the net), with electricity supplied by a solar-powered system (Gallagher S2O, Gallagher, Hamilton, New Zealand). The cost of the net and poles (including transportation from Ulaanbaatar) was c. USD 600 per fence and the solarpowered system was c. USD 400 per fence, of which c. USD 140 was for the wire, insulators and grounding kit. Where possible, we built the fences around the existing corrals to retain shelter from the wind. However, this was not always possible as some of the corrals were too large or there were too many structures adjacent to

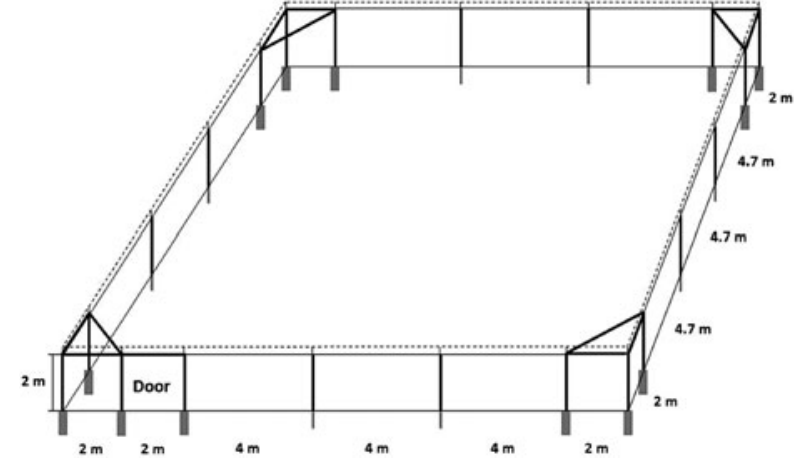

FIG. 2 Schematic drawing of the fences built to reduce livestock losses at night-time corrals in the Tost Mountains in southern Mongolia. The electrical wire at the top of the fence is shown by the dashed line. Corner poles and corner-support poles were supported by cement (grey rectangles), whereas the other poles were driven into the ground without any additional support (thin grey lines). We recommend installing poles every $2 \mathrm{~m}$ to make the fence stronger.

the corrals that could be used by snow leopards to cross the fences.

\section{Statistical analyses}

We examined whether the fences reduced losses of herded livestock at the winter corrals with a $\chi^{2}$ test, comparing losses of herded livestock the winter before the fences were built with losses of herded livestock in the two winters after the fences were built $(n=27$ losses from seven fenced corrals and three winters). We also examined whether the losses of herded livestock in the pastures in winter and when at the summer camps during the rest of the year differed before and after we built the fences by using a $\chi^{2}$ test $(\mathrm{n}=123$ losses from seven fenced corrals and 2 years). We 
TABLE 1 Mean number of self-reported losses of herded livestock (goats and sheep) per family and year to snow leopards Panthera uncia and wolves Canis lupus at night-time corrals and pastures in the Tost Mountains, Mongolia, before fences were built. The range of losses is provided in parentheses and the information is based on self-reported losses by 6o herder families.

\begin{tabular}{llll}
\hline \multirow{2}{*}{ Predator } & \multicolumn{4}{l}{ Mean number (and range) of herded livestock losses during spring 2013-spring 2014 } \\
\cline { 2 - 4 } & Night-time losses at camps & Daytime losses in pastures & Total losses \\
\hline Snow leopard & $0.7(0-10)$ & $0.7(0-10)$ & $1.4(0-17)$ \\
Wolf & $3.2(0-20)$ & $3.9(0-30)$ & $7.1(0-50)$ \\
Both predators & $3.9(0-20)$ & $4.6(0-30)$ & $8.5(0-50)$ \\
\hline
\end{tabular}

further examined whether losses of herded livestock prior to building the fences in 2014 differed by predator species (snow leopard vs wolf), time of day (night vs day), and season (winter vs rest of the year) by using $\chi^{2}$ tests, whereby we performed the comparisons for time of day and season separately for snow leopards and wolves $(n=512$ losses; reduced to 460 losses for the seasonal analyses because information on time of year was missing for some losses in the pastures).

We examined whether the attitudes of the herder community (i.e. all 6o herder families interviewed) towards snow leopards and towards wolves differed before building the fences. We examined whether the fences affected the herder community's attitudes towards snow leopards and wolves, also with an ANOVA, comparing herder attitudes before and after the fences were built, with separate analyses for snow leopards and wolves (6o families interviewed before and 20 after the fences were built). Similarly, we examined whether the fences affected the attitudes of the herders that received fences, using a paired $t$ test to compare herder attitudes before and after the fences were built, whereby we performed the analyses separately for snow leopards and wolves (seven families interviewed before and after the fences were built). We performed all analyses in the statistical software $R$ 3.5.1 (R Development Core Team, 2014).

\section{Results}

\section{Livestock losses prior to building fences}

Mean livestock holding per family in the herder community in the spring of 2014 was 401 livestock (range= 95-934), which included 368 goats (range $=90-820$ ), 21 sheep (range $=0-80$ ), five horses (range $=0-50$ ) and seven camels per family (range $=0-60$ ). All but one of the 60 families interviewed in the spring of 2014 had at least one dog, with a mean of 2.1 dogs per family (range = o-5). Most families (43 out of $60 ; 72 \%$ ) had a corral at their winter camp.

The mean annual loss of herded livestock to predation by snow leopards and wolves during spring 2013-spring 2014 was 8.5 goats and sheep per family and year (range $=0-50$;
Table 1), which corresponds to a mean annual loss of c. $3 \%$ of the herded livestock holding per family and year (range $=0-19 \%)$. More herded livestock were lost to wolves than to snow leopards in the year prior to the study $\left(\chi_{(1)}^{2}=228, \mathrm{P}<0.001\right.$; Table 1$)$, with a mean annual loss of 7.1 goats and sheep per family and year to wolves (range = 0-50) vs 1.4 goats and sheep per family and year to snow leopards (range $=0-17$ ). Night-time losses of goats and sheep at herder camps were similar to daytime losses of goats and sheep in the pastures for both snow leopards $\left(\chi_{(1)}^{2}=0.106, \mathrm{P}=0.74\right)$ and wolves $\left(\chi_{(1)}^{2}=3.56, \mathrm{P}=0.059\right)$ in the year prior to the study: mean livestock losses to snow leopards at night-time camps and on the pastures were 0.7 and 0.7 goats and sheep per family and year, respectively, and mean livestock losses to wolves at night-time camps and on the pastures were 3.2 and 3.9 goats and sheep per family and year, respectively (Table 1). Losses of herded livestock to snow leopards occurred almost exclusively in winter $(94 \%)$ when herders were in the mountains $\left(\chi_{(1)}^{2}=55.9\right.$, $\mathrm{P}<0.001$ ), whereas losses of herded livestock to wolves in winter $(46 \%)$ were similar to the losses during the rest of the year $(54 \%)$ when most herders were out on the steppe $\left(\chi_{(1)}^{2}=2.16, \mathrm{P}=0.14\right)$.

\section{Livestock losses after building fences}

There were no losses of herded livestock at any of the 10 fenced corrals in either of the two winters of this study: the mean loss of herded livestock for the families that received fences decreased from 3.9 goats and sheep per family in the winter prior to the study (range $=0-13$ ) to zero losses of goats and sheep in the two winters of the study $\left(\chi_{(2)}^{2}=54\right.$, $\mathrm{P}<$ o.001; Table 2). The mean loss of herded livestock when in pastures in winter and when at the summer camps during the rest of the year for these families, in contrast, was greater in the last year of the study than during the year prior to the study $\left(\chi_{(1)}^{2}=5.17, \mathrm{P}=0.023\right.$; Table 3$)$. Specifically, the mean loss of herded livestock when in the pastures in winter and when at the summer camps during the rest of the year for these families was 6.9 (range = o-23) and 10.4 (range $=4-21$ ) goats and sheep per family and year in the year prior to the study and in the last year of the study, respectively. 
TABLE 2 Mean number of self-reported losses of herded livestock (goats and sheep) per family at winter camps, before and after the fences were built. The range of losses is provided in parentheses and the information is based on self-reported losses by seven herder families. Fences were built only at winter camps and thus did not reduce losses during the rest of the year (except for one family that did not move and used the fenced corral year-round).

\begin{tabular}{llll}
\hline & \multicolumn{2}{l}{ Mean number (and range) of herded livestock losses at fenced camps } \\
\cline { 2 - 4 } & \multicolumn{2}{l}{ Before building fences } & After building fences \\
\cline { 2 - 4 } Predator & Winter 2013-2014 & Winter 2014-2015 & Winter 2015-2016 \\
\hline Snow leopard & $2.4(0-10)$ & 0 & 0 \\
Wolf & $1.4(0-3)$ & 0 & 0 \\
Both predators & $3.9(0-13)$ & 0 & 0 \\
\hline
\end{tabular}

TABLE 3 Mean number of self-reported losses of herded livestock (goats and sheep) per family when away from the fences (i.e. when in the pastures in winter and during the rest of the year, with the latter referred to as summer in the table) for families that received fences, before and after the fences were built. The range of losses is provided in parentheses and the information is based on self-reported losses by seven herder families. Fences were built only at winter camps and thus did not reduce losses during the rest of the year (except for one family that did not move and used the fenced corral year-round).

\begin{tabular}{|c|c|c|c|c|c|c|}
\hline \multirow[b]{3}{*}{ Predator } & \multicolumn{6}{|c|}{ Mean number (and range) of herded livestock losses away from fences } \\
\hline & \multicolumn{3}{|c|}{ Before building fences } & \multicolumn{3}{|c|}{ After building fences } \\
\hline & $\begin{array}{l}\text { Summer } 2013 \\
\text { at camps }\end{array}$ & $\begin{array}{l}\text { Summer } 2013 \\
\text { at pastures }\end{array}$ & $\begin{array}{l}\text { Winter } 2013 / 2014 \\
\text { at pastures }\end{array}$ & $\begin{array}{l}\text { Summer } 2015 \\
\text { at camps }\end{array}$ & $\begin{array}{l}\text { Summer } 2015 \\
\text { at pastures }\end{array}$ & $\begin{array}{l}\text { Winter } 2015 / 2016 \\
\text { at pastures }\end{array}$ \\
\hline Snow leopard & 0 & 0 & $1.7(0-7)$ & 0 & $0.1(0-1)$ & $4.6(0-20)$ \\
\hline Wolf & $0.7(0-4)$ & $1.0(0-6)$ & $3.4(0-8)$ & $0.4(0-3)$ & $2.6(0-9)$ & $2.7(0-10)$ \\
\hline Both predators & $0.7(0-4)$ & $1.0(0-6)$ & $5.1(0-13)$ & $0.4(0-3)$ & $2.7(0-9)$ & $7.3(0-21)$ \\
\hline
\end{tabular}

Attitudes towards snow leopards and wolves before and after building fences

The herder community's attitude in the spring before we built the fences was positive towards snow leopards and negative towards wolves $(\mathrm{F}=136, \mathrm{P}<0.001)$, with mean attitudes scores of $2.6 \pm \mathrm{SD} 2.7$ and $-2.9 \pm \mathrm{SD} 2.5$ ), respectively. After 2 years of the study, the herder community's attitude towards snow leopards appeared to have improved further (mean attitude score $3.8 \pm \mathrm{SD} 2.8$ ), although the increase in attitude score was significant only at $\alpha=0.10$ $(\mathrm{F}=2.94, \mathrm{P}=0.091)$. The herder community's attitude towards wolves, in contrast, had become more negative (mean attitude score $-4.3 \pm \mathrm{SD}$ 1.6; $\mathrm{F}=5.29, \mathrm{P}=0.024$; Fig. 3). Similarly, the attitudes of the families who had received the fences also appeared to have improved towards snow leopards (Fig. 3), although the apparent increase was not statistically significant $(t=0.982, \mathrm{P}=0.36)$. The attitudes of the families that received the fences were more negative towards wolves after the 2 years of our study $(t=2.96, \mathrm{P}=0.025$; Fig. 3$)$.

\section{Discussion}

Livestock depredation by snow leopards and wolves inside poorly constructed corrals is a major challenge for herders
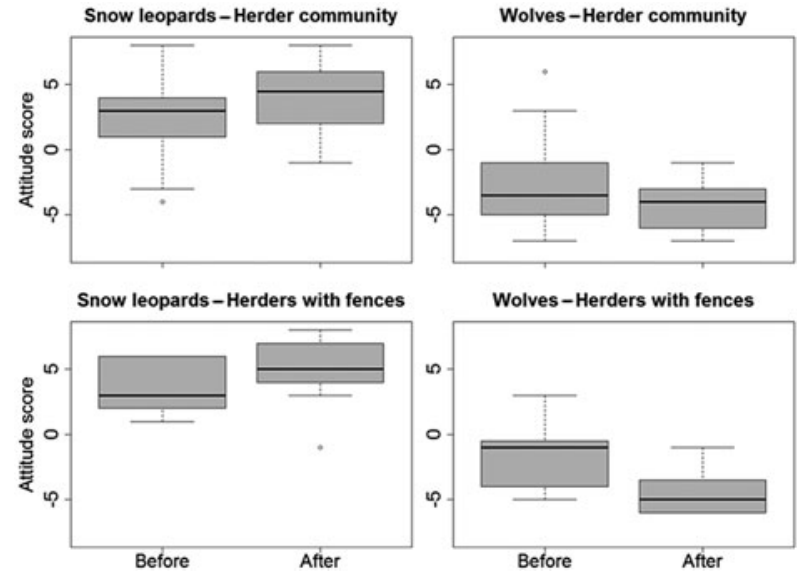

Fig. 3 Herders' attitudes toward snow leopards (left panels) and wolves (right panels) before and after the fences were built, with top panels showing attitudes of all herders interviewed (6o families) and the bottom panels showing attitudes of the families that received fences (seven families). Our attitude survey followed the protocol by Suryawanshi et al. (2014), with attitude scores ranging from -8 (very negative) to +8 (very positive), with o being a neutral score.

in the mountains of central Asia (Jackson \& Wangchuck, 2004; Namgail et al., 2007; Mohammad et al., 2016). In this study, we found that fences were effective at reducing nighttime depredation at corrals, similar to the effects of predator 
proofing houses and other structures elsewhere (Jackson \& Wangchuck, 2004; Lichtenfeld et al., 2015; Mohammad et al., 2016). Our study also showed that herders' attitudes towards snow leopards remained positive and may even have improved during the study, suggesting that fences can be an important tool for snow leopard conservation and for facilitating the coexistence of snow leopards and people in areas with similar conditions as in our study. However, the positive and potentially improving attitude towards snow leopards may also be a result of other snow leopard conservation efforts in the study area, such as an insurance programme and a handicraft programme to provide supplemental income (Mishra et al., 2003). The potential impact of fences on herders' attitudes thus warrants further examination. Herders' attitudes towards wolves, in contrast, were more negative after the fences had been built. It is possible that the difference in the timing of the surveys affected the attitude scores because the survey at the end of the study was done after the herders had moved out on the steppes, where they suffered losses only to wolves, which may have kept losses to wolves more fresh in herders' minds and therefore worsened the attitudes towards the wolves. Increasingly negative attitudes towards wolves could also have been a consequence of our conservation programmes focusing on snow leopards, whereas the conservation efforts for wolves have been minimal. This imbalance in conservation efforts could have led to the perception that fences were provisioned as part of our conservation actions for snow leopards, possibly resulting in worsening attitudes towards wolves. This possibility will need to be addressed in future interventions.

The herder community in the Tost Mountains suffered substantial livestock losses to snow leopards and wolves, with $c$. half of the losses of herded livestock occurring at night-time corrals. Depredation inside night-time corrals can be devastating as it often results in mass killings, with substantial negative impacts on herder economy and emotional well-being, which may lead to retaliatory and preventive killing of predators (Jackson \& Wangchuck, 2004). In our study area at least one and possibly three GPS-collared snow leopards were killed during a 5-year period in response to repeated attacks on livestock at night-time corrals (Johansson et al., 2015). Developing measures to reduce night-time losses is thus crucial for establishing conditions that enable coexistence of snow leopards and people. Although there were no livestock losses to snow leopards or wolves in the fenced corrals during this study, we stress that the fences may not offer complete protection as it may be possible for predators to jump over or dig under the fences. Nevertheless, our study showed that fences are effective at reducing livestock losses at night-time corrals and thus offer a good alternative to predator-proofing in situations in which it is not possible or cost effective to build predator-proof structures (see Jackson \& Wangchuck, 2004 for predator-proof structures).
The herders expressed high satisfaction with the fences but also suggested making the fences larger to avoid crowding and using more poles to make the fences stronger. If the fences are too small, herders may keep part of the herd outside the fence to avoid negative effects on livestock health or wool quality (see Berger et al., 2013 for the importance of wool for herder economies). The herders also suggested complementing the fences with some type of wind shelter as the wind has a strong cooling effect in winter. We therefore suggest building fences around existing corrals when possible to use the existing corral walls for wind protection, or attaching wooden planks to the lower parts of the inside of the fence when fences cannot be built around existing corrals. Adding planks may, however, require more poles to support the fence as the planks will catch the wind and increase the forces exerted on the fence. The herders also suggested that the electrical wire at the top of the fence could be removed without affecting fence effectiveness as wolves generally do not climb and it is unlikely that snow leopards would climb the fences. We nonetheless recommend keeping the wire at the top of the fence because predators may climb in some situations. Field visits showed that the fences generally lasted well but that they tended to need some minor repairs such as adding soil or rocks to places where the soil had washed away under the fence. Burying the bottom $20-30 \mathrm{~cm}$ of the net in the ground when installing the fences could prevent the forming of holes at the bottom of the fences and would also provide additional support for the fences, but we stress that maintenance remains important to ensure the effectiveness and longevity of the fences.

Integrating the fences assessed in this study into a permanent conservation programme is hampered by the relatively high cost of the materials for the fences. For this study we bought the material and worked out an arrangement with the recipient families to repay the cost over 2-3 years. This meant that the herders did not have to cover the cost in a single payment but instead could spread the cost over time. We suggest that proper maintenance of the fences and targeting of areas with high predation pressure are important for the sustainability of a conservation programme using fences to reduce livestock losses following recommendations by Mohammad et al. (2016). It is also important to build fences so that they do not restrict herder movements between camps, as this could result in increased grazing pressure and pasture degradation around fenced camp sites. This could be achieved by building fences at more than one camp site or by developing a design that allows for fences or parts of the fences to be moved between camp sites. We also recommend that the use of fences to reduce livestock losses is combined with other conservation measures, as a multipronged approach with several conservation efforts often provides more favourable outcomes than single solutions, even when those appear to be highly 
effective (Jackson \& Wangchuck, 2004; Suryawanshi et al., 2014; Mishra et al., 2017).

In summary, this study showed that fences can be effective at reducing livestock losses at night-time corrals and that herders' attitudes towards snow leopards remained high throughout the study. We therefore conclude that fences can be an important tool for snow leopard conservation and for facilitating the coexistence of snow leopards and people in areas with similar conditions to our study area.

Acknowledgements We dedicate this article to our friend and colleague Lkhagvasumberel Tumursukh who was crucial for initiating this study and for much of our work in the Tost Mountains. We thank the People's Trust for Endangered Species for funding and two anonymous reviewers for valuable suggestions that improved the manuscript.

Author contribution Study design: GS, KS, JF, BA, LT, ÖJ, CM; data collection: EB, TM, LT; data analysis: GS, KS; writing: all authors.

\section{Conflict of interest None.}

Ethical standards This research abided by the Oryx guidelines on ethical standards.

\section{References}

Aryal, A., Brunton, D., Ji, W., Barraclough, R.K. \& Raubenheimer, D. (2014) Human-carnivore conflict: ecological and economical sustainability of predation on livestock by snow leopard and other carnivores in the Himalaya. Sustainability Sciences, 9, 321-329.

Berger, J., Buuveibaatar, B. \& Mishra, C. (2013) Globalization of the cashmere market and the decline of large mammals in Central Asia. Conservation Biology, 27, 679-689.

Eklund, A., López Bao, J.V., Tourani, M., Chapron, G. \& Frank, J. (2017) Limited evidence on the effectiveness of interventions to reduce livestock predation by large carnivores. Scientific Reports, 7, 2097.

Inskip, C. \& Zimmermann, A. (2009) Human-felid conflict: a review of patterns and priorities worldwide. Oryx, 43, 18-34.

JACKSON, R.M. \& WANGCHUCK, R. (2004) A community-based approach to mitigating livestock depredation by snow leopards. Human Dimensions of Wildlife, 9, 307-315.

Johansson, O., McCarthy, T., Samelius, G., Andrén, H., Tumursukh, L. \& Mishra, C. (2015) Snow leopard predation in a livestock dominated landscape in Mongolia. Biological Conservation, 184, 251-258.

Li, J., Yin, H., WanG, D., Jiagong, Z. \& Lu, Z. (2013) Human-snow leopard conflicts in the Sanjiangyuan Region of the Tibetan Plateau. Biological Conservation, 166, 118-123.

Lichtenfeld, L.L., Trout, C. \& Kisimir, E.L. (2015) Evidence-based conservation: predator-proof bomas protect livestock and lions. Biodiversity and Conservation, 24, 483-491.

Mijiddorj, T.N., Alexander, J.S. \& Samelius, G. (2018) Livestock depredation by large carnivores in the South Gobi, Mongolia. Wildlife Research, 45, 237-246.

Mishra, C., Allen, P., McCarthy, T., Madhusudan, M.D., Agvanntserenginn, B. \& Prins, H.H.T. (2003) The role of incentive programs in conserving the snow leopard. Conservation Biology, 17, 1512-1520.

Mishra, C., Rutherford, B., Thinley, T., Sonam, K., Bijoor, A., Timbadia, R. et al. (2016) Setting up mechanisms to offset wildlife-caused economic damage: community-based livestock insurance. In The PARTNERS Principles for Community-Based Conservation (ed. C. Mishra), pp. 127-148. Snow Leopard Trust, Seattle, USA.

Mishra, C., Young, J.C., Fiechter, M., Rutherford, B. \& Redpath, S.M. (2017) Building partnerships with communities for biodiversity conservation: lessons from Asian mountains. Journal of Applied Ecology, 54, 1583-1591.

Mohammad, G., Mostafawi, S.N., Dadul, J. \& Rosen, T. (2016) Corral improvement. In Snow Leopard (eds T. McCarthy \& D. Mallon), pp. 180-183. Elsevier, New York, USA.

Namgail, T., Fox, J.L. \& Bhatnagar, Y.V. (2007) Carnivore-caused livestock mortality in Trans-Himalaya. Environmental Management, 39, 490-496.

R Development Core Team (2014) R: a Language and Environment for Statistical Computing. R Foundation for Statistical Computing, Vienna, Austria. Rproject.org [accessed 26 July 2019].

Suryawanshi, K.R., Bhatia, S., Bhatnagar, Y.V., Redpath, S. \& Mishra, C. (2014). Multiscale factors affecting human attitudes toward snow leopards and wolves. Conservation Biology, 28, $1657-1666$.

Treves, A. \& Karanth, K.U. (2003) Human-carnivore conflict and perspectives on carnivore management worldwide. Conservation Biology, 17, 1491-1499.

van Eeden, L.M., Eklund, A., Miller, J.R., López-Bao, J.V., Chapron, G., Cejtin, M.R. et al. (2018) Carnivore conservation needs evidence-based livestock protection. PLOS Biology, 16, e2005577.

Woodroffe, R., Thirgood, S.J. \& Rabinowitz, A. (2005) People and Wildlife, Conflict or Co-Existence? Cambridge University Press, Cambridge, UK. 